\title{
Digital Publishing Production Processes for Education
}

\author{
Chaiwat Garnrunsri, Prachyanun Nilsook, and Panita Wannapiroon
}

\begin{abstract}
This research purposed (1) to create a conceptual framework of digital publishing production processes for education (2) to evaluate the appropriateness of processes according to the framework. The processes of this research were (1) synthesizing digital publishing production processes for education from documents and related research (2) creating a conceptual framework from digital publishing production processes for education (3) evaluating the appropriateness of processes according to the Conceptual framework by producing a questionnaire to evaluate the suitability of processes, with the evaluation of the reliability being done by 5 experts (4) making corrections according to the advice and evaluation by 15 experts in digital publishing production processes according to the appropriateness of the conceptual framework. The instrument used in this research is a questionnaire about the appropriateness of the processes. The statistics used in analyzing data are mean and standard deviation. The results found that (1) the conceptual framework of digital publishing production processes for education consisted of 3 subprocesses as follows. (1.1) Digital content creation processes, including 4 steps of editorial and planning analysis, digital content design, collecting, editing, and creating digital content, and digital content classification. (1.2) Digital assets management processes, including 3 steps of ingestion and selection of digital content type, annotation and cataloging, and storage. (1.3) Digital publishing production processes, including 4 steps of digital publishing design, component integration and development, testing and quality assurance, and creating digital rights management. (2) The results of the evaluation of the appropriateness of digital publishing production processes for education by experts in digital publishing production processes for education found that they are most appropriate overall.
\end{abstract}

Index Terms-Digital asset, digital content, digital publishing.

\section{INTRODUCTION}

In Thai education, traditional publication is one of the main educational media and is used from kindergarten to university level. However, many people are less interested in traditional publication because of digital publishing. Students can easily assess this kind of media and it is more interesting because it is more special than ordinary publication because of 2 features. The first feature is that this media can include a lot of media for reading, listening, and watching. Another feature is that users can interact with this media [1]. As a

Manuscript received October 12, 2019; revised December 4, 2019.

C. Garnrunsri is with the Department of Technical Education Technology in the Faculty of Technical Education, King Mongkut's University of Technology North Bangkok (KMUTNB), Bangkok, Thailand (e-mail: chaiwat@maceducation.com).

P. Nilsook and P. Wannapiroon are with the Faculty of Technical Education, King Mongkut's University of Technology North Bangkok (KMUTNB), Bangkok, Thailand (e-mail: prachyanun.n@fte.kmutnb.ac.th, panitaw@kmutnb.ac.th). result, producers cannot deny the rapid development of digital publishing. They also need to adapt to the new trend and the users' demand. Digital publishing apply interactive systems to link content, animation and sound, which can grab users' attention. Digital publishing are usually designed by combining virtual reality, visualization, simulation, and 3D animation, as well as the other technologies. This type of publication can enhance the efficiency of the digital publication industry [2]. Besides, the educational media will be changes from traditional publishing to digital publishing, this technology takes part in every process of the publication industry, such as content management development, change of production process, and the idea of using ordinary publication. These elements show the trend of the digital publication industry in the 21st century [3] and this media affects the strategies of publication development in many countries [4].

There are various kinds of media, but many people use e-books, which can be divided into 4 categories: text-based e-book, multimedia e-book, interactive e-book, and resource-based e-book [5]. Each e-book has the same and different processes, so the overall production consists of many steps. The first step is creating digital content in terms of message, image, audio, visualization, and animation. The next step is storing digital content systemically. The last step is combining the digital content in step 2 in order to produce a digital publishing. Some research has studied the digital publishing steps and production processes but these works have not studied each step in detail. As a result, the current researchers would like to study all the digital publishing processes in an educational production context and to create a conceptual framework of digital publishing because organizations have their own production processes, so there are varieties of production processes. The processes of each organization do not have the same standards. Standardization is an appropriate way to produce and develop. As a result, the researchers are interested in studying and creating a conceptual framework of digital publishing to standardize the development of processes for digital publication in educational institutions. It can then be applied to digital publishing processes effectively.

\section{RESEARCH OBJective}

1) To create a conceptual framework of digital publishing processes for education.

2) To evaluate the appropriateness of processes according to the concept.

\section{RESEARCH PROCESSES}

There are 2 phases in this research as follows: 
The first phase: to create a conceptual framework of digital publishing processes for education.

1) Analyze and synthesize the processes of digital publishing for education from documents and research works of [3],
[6]-[13]. After that, apply these data to synthesize the conceptual framework of digital publishing processes for education.

TABLE I: Synthesize the Digital PUBLISHING PRODUCTION PROCESSES FOR EDUCATION

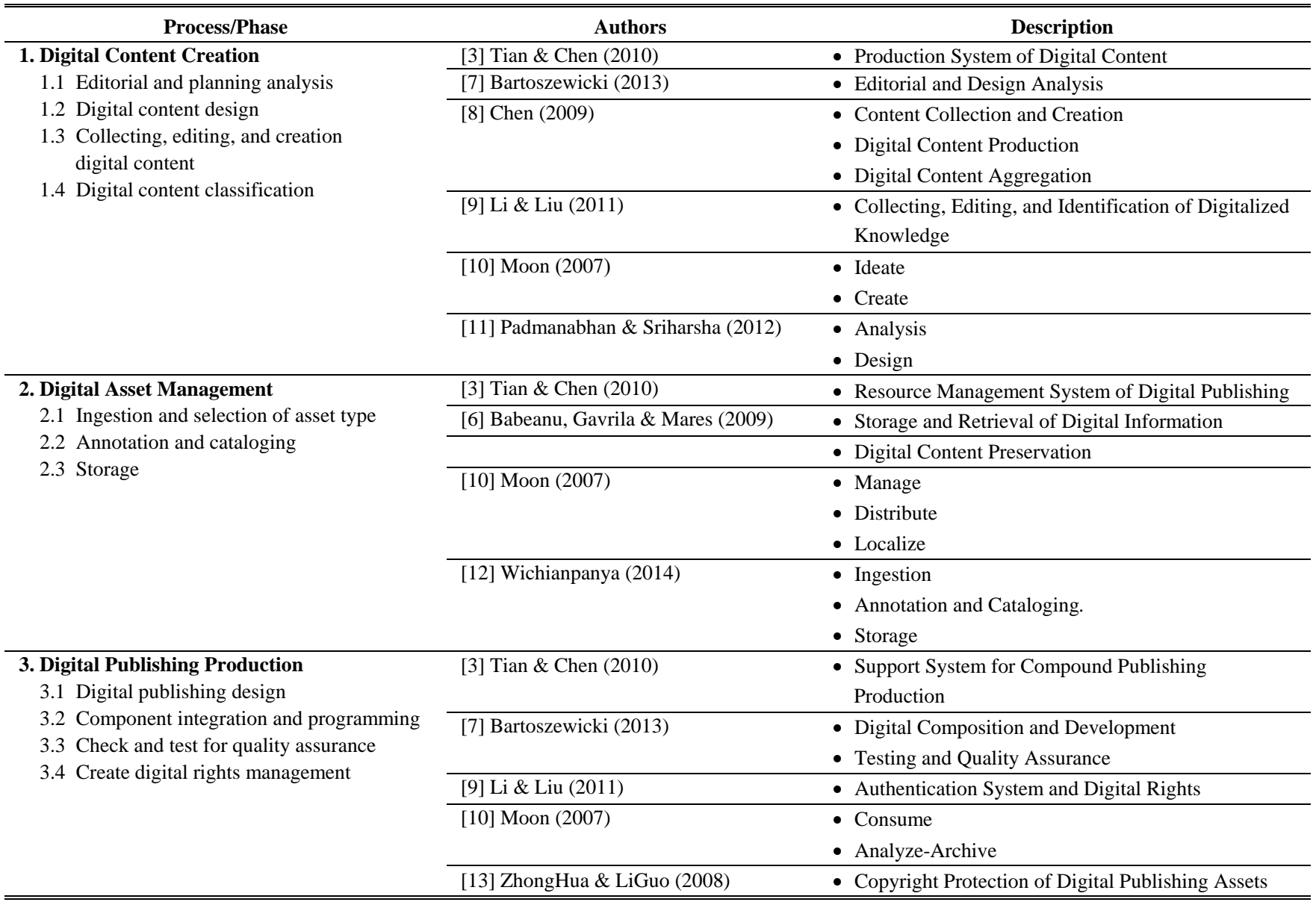

According to Table I, the synthesis of digital publishing processes for education consists of 3 minor processes: 1) digital content creation, 2) digital asset management, and 3) digital publishing production. The data will be discussed as follows.

Tian and Chen [3] did research on the "Architecture of the Digital Publishing Management System". They found that the publishing management system consisted of 4 main systems: 1) the production system of digital content, 2) the asset management system of digital publishing management, 3 ) the support system for compound publishing production, and 4) the top service system of digital publishing production.

Chen [8] explained about digital content in the research "Analysis of the Digital Content Industry Value Chain". The digital content industry value chain consists of 5 elements: 1) content collection and creation, 2) digital content production, 3) digital content aggregation, 4) digital content transmission and distribution, and 5) end-user.

Padmanabhan and Sriharsha [11] outlined 4 processes to gain income from digital content: 1) analysis, 2) design, 3) selecting tools and technologies, and 4) implementation.

Bartoszewicki [7] explained the processes of production interactive electronic books in the book "Designing and Building an Interactive eBook". It consists of 3 phases: 1) editorial and design analysis, 2) digital composition and development, and 3) testing and quality assurance.

Li and Liu [9] analyzed the phases of digital publishing operations in their research "Workflow and its Implementation of Digital Publishing Based of KaaS. They found that production of digital publishing is a process with elements as follows: 1) collecting, editing, and identification of digitalized knowledge, 2) authentication system and digital rights management of knowledge, and 3) distribution and exchange of knowledge.

Wichianpanya [12] presented ideas about content management systems and digital asset management. These consisted of 5 phases: 1) ingestion, 2) annotation and cataloging, 3) storage, 4) retrieval, and 5) distribution.

Babeanu, Gavrila and Mares [6] did research into the topic "Strategic Outlines: Between Value and Digital Assets Management". They found that digital asset management consists of 4 elements: 1) storage and retrieval of digital information, 2) digital content preservation, 3) hardware and software management, 4) backup and recovery, 5) authenticity and security of document, and 6) metadata.

Moon [10] also did research about the "Cycle Time Activity Lifecycle of Digital Assets". This research concluded that digital asset management has 7 phases. The first phase is the "ideate phase", during which the researcher 
develops their idea or plans the processes. The second phase is the "create phase", the phase of creating the digital asset. The third phase is the "manage phase" the phase of managing database and digital asset analysis. The fourth phase is the "distribute phase", the phase of collecting and distributing digital assets. The fifth phase is the "localize phase", including the copy and recheck of the digital asset. The sixth phase is the "consume phase"; this is the phase of doing digital copyright. The last phase is the "analyze-achieve phase": the phase of analyzing and improving the digital asset and maintaining it permanently.

ZhongHua and LiGuo [13] did research into digital publishing resource management in China. They found that the copyright of digital publishing is an important aspect of the digital publishing resources management. Copyright protection could guarantee for publishing industry because it was to protect the authors and protect the intellectual property from copyright infringement.

2) Design the conceptual framework of digital publishing production processes was designed based on this synthesized research. It is called "Digital publishing production processes for education framework" and consists of 3 processes: digital content creation process, digital asset management process and digital publishing production process.

The second phase was the evaluation for appropriateness of processes according to the conceptual framework. A questionnaire for appropriateness of digital publishing processes was created, then it was checked for reliability by 5 experts. The researchers applied the results to improve the questionnaire. After that, this questionnaire was checked by 15 experts in digital publishing production in order to evaluate the processes.

\section{RESULTS}

The results of this research can be concluded as follows.

Phase 1: Conceptual framework of digital publishing production processes for education

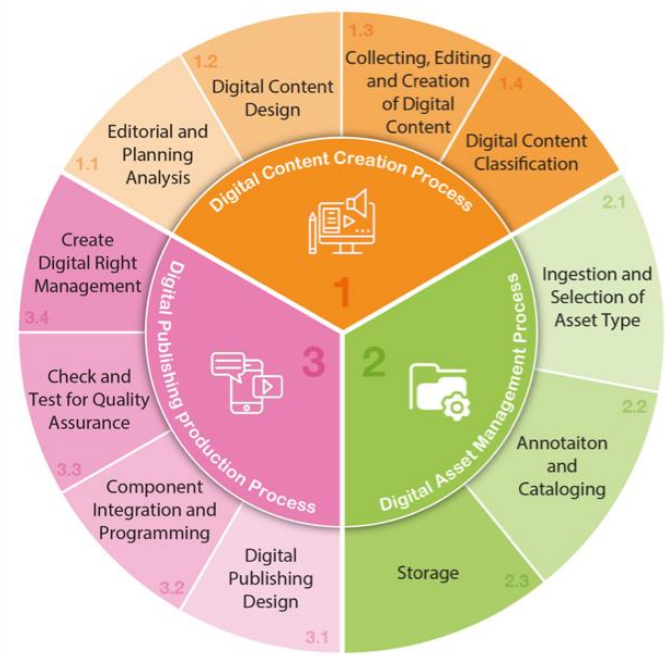

Fig. 1. Conceptual framework of digital publishing production processes for education.

As seen in Fig. 1, these processes can be divided into 3 processes as follows:

\section{1) Digital Content Creation Process}

The digital content creation process means changing the ordinary publishing content into a digital media product. The ordinary publishing content could produce many digital contents [8]. The digital content creation process means planning, designing and preparing digital files to categorize them then include them in digital publishing. This process consists of 4 processes as follows:

1.1 Editorial and Planning Analysis: Producers need to content analysis to determine format of digital publishing and planning analysis to determine production flow of digital publishing in order to design and develop the content into digital publishing [11].

1.2 Digital Content Design: This part identifies detail for presenting the content after determining the digital publishing format. This step makes the content more interesting than ordinary publishing. The most important factor for designing digital content is the content management by connecting the content in each part to be easy to understand. The second factor is the design of content presentation to help stimulate interest and ease of reading. it is a step of designing all elements of digital publishing such as content format and detailed description [7]. This is called the creation of a storyboard.

1.3 Collecting, Editing and Creation of Digital Content: After doing the storyboard, the next steps are collecting, editing and creation of digital content according to the storyboard.

1.4 Digital Content Classification: This is the step of preparing digital content files before the digital asset management process. These files are modified into message files, pictures, audio files and animations then transferred to a digital asset database to be easy to keep and search for the next time.

\section{2) Digital Asset Management Process}

The production of digital publishing needs to deal with the steps for collecting, editing, storing, and implementing of digital content in order to support the reuse of the same piece. This decreases the budget in producing digital publishing and decrease the mistakes. The digital asset management process consists of 3 main phases as follows:

2.1 Ingestion and Selection of Asset Type: Each Digital content has many formats, which depend on instruments to produce the ordinary files.. Applying these files in production departments needed to transform digital files into the same standard as well as categorizing the digital files by determine digital ID to these files for ease of use [12].

2.2 Annotation and Cataloging: These files are not designed to be searched for using ordinary words. Giving keywords to the digital file is a way to facilitate searching the file. It is begun by categorizing data and determining data. After that, this digital data is transferred into metadata, which are used for searching [12].

2.3 Storage: This is step of storing digital content files that have already been organized. We call digital content stored in this step as Digital assets.

3) Digital Publishing Production Process

The digital publishing production process is the last phase, which integrates the digital content then systematizes the digital asset management processes. The digital publishing 
production process collects these contents according to the storyboard, which consists of 4 phases as follows:

3.1 Digital Publishing Design: Digital publishing is more special than ordinary publishing because digital publishing is more varied and interesting. It can change dull data to be more attractive. It can connect content to readers with colorful figures and animated pictures. Moreover, it can be imbedded in links to many websites if readers need more information. In designing and producing digital publishing, one has to be concerned about technical and psychological aspects. As for the technical aspect, the design must considered the size, color, font, the program used in the display, etc. The colors and sizes of letters, and design of figures and layout would be identified in the storyboard. However, they require some detail and adjustment to be most appropriate.

3.2 Component Integration and Programming: This is a step that is produced by experts in the storyboard. After that, this step produces the digital publishing according to the storyboard by using digital content such as messages, figures, audios, and animations, which are kept in the digital asset warehouse. This content is combined then connected according to the storyboard. Technical experts have to cooperate with digital content producers and program designers in order to solve some problems; for example, if some components were lost during the designing process, this problem will be returned to the designers and editors to ask some advice until the processes are finished [7].

3.3 Check and Test for Quality Assurance: This phase checks and tests to assure the quality of the digital publishing. The standard of the checking needs to be taken seriously to get good quality digital publishing. The first step is that producers check the letters and content in the digital content and the ordinary content to confirm they are correct then experiment deeply to know that every platform could work [7].

3.4 Create Digital Rights Management: This management is for the copyright owners who can duplicate and publish the digital publishing in many ways and prohibit other people from infringing the copyright. Copyright owners are necessary for digital publishing resource management [13].

Phase 2: The appropriateness of the processes

In the analysis of the appropriateness of the digital publishing production processes for education, the statistics used are arithmetic mean and standard deviation. These formulas were Best and Kahn's [14] criteria for evaluation and are divided into 5 ratings according to Likert's scale [15] as follows:

$\begin{array}{lll}5 & \text { means } & \text { the most appropriate } \\ 4 & \text { means } & \text { more appropriate } \\ 3 & \text { means } & \text { quite appropriate } \\ 2 & \text { means } & \text { less appropriate } \\ 1 & \text { means } & \text { the least appropriate }\end{array}$

The score range for setting the rate of mean is as follows:

Mean 4.50-5.00 means the most appropriate

Mean 3.50-4.49 means more appropriate

Mean 2.50-3.49 means quite appropriate

Mean 1.50-2.49 means less appropriate

Mean 1.00-1.49 means the least appropriate

The results of the evaluation of the appropriateness of digital publishing production processes for education are shown in Table II.

TABLE II: THE RESUlt OF EVALUATING APPROPRIATENESS OF DIGITAL PUBLISHING PRODUCTION PROCESSES FOR EDUCATION

\begin{tabular}{|c|c|c|c|c|}
\hline & \multirow{2}{*}{ Description } & \multicolumn{3}{|c|}{ Result } \\
\hline & & $\bar{x}$ & S.D. & Rating \\
\hline \multirow[t]{5}{*}{1.} & Digital Content Creation Process & 4.73 & 0.56 & the most appropriate \\
\hline & 1.1 Editorial and Planning Analysis & 4.93 & 0.26 & the most appropriate \\
\hline & 1.2 Digital Content Design & 4.93 & 0.26 & the most appropriate \\
\hline & 1.3 Collecting, Editing, and Creation Digital Content & 4.87 & 0.35 & the most appropriate \\
\hline & 1.4 Digital Content Classification & 4.80 & 0.41 & the most appropriate \\
\hline \multirow[t]{4}{*}{2.} & Digital Asset Management Process & 4.72 & 0.58 & the most appropriate \\
\hline & 2.1 Ingestion and Selection of Asset Type & 4.87 & 0.35 & the most appropriate \\
\hline & 2.2 Annotation and Cataloging & 4.87 & 0.35 & the most appropriate \\
\hline & 2.3 Storage & 4.80 & 0.56 & the most appropriate \\
\hline \multirow[t]{6}{*}{3.} & Digital Publishing Production Process & 4.76 & 0.49 & the most appropriate \\
\hline & 3.1 Digital Publishing Design & 4.87 & 0.35 & the most appropriate \\
\hline & 3.2 Component Integration and Programming & 4.87 & 0.35 & the most appropriate \\
\hline & 3.3 Check and Test for Quality Assurance & 4.73 & 0.59 & the most appropriate \\
\hline & 3.4 Create Digital Rights Management & 4.93 & 0.26 & the most appropriate \\
\hline & Overall Score & 4.73 & 0.54 & the most appropriate \\
\hline
\end{tabular}

According to Table II, the evaluation of each process is as follows:

1) . Evaluation of the content production process found that the mean was 4.73 and standard deviation was 0.56 . As a result, the content production process was rated as most appropriate.

2) Evaluation of the digital asset process management found that the mean was 4.72 and standard deviation was 0.58 . As a result, the digital asset process management was rates as most appropriate.
3) Evaluation of the digital publishing production process found that the mean was 4.76 and standard deviation was 0.49. As a result, the digital publishing production process was rated as most appropriate.

4) Evaluation of the overall processes of the digital publishing production process found that the mean was 4.73 and standard deviation was 0.54 . As a result, the overall processes were rated as most appropriate. 


\section{CONCLUSION}

The producers of educational media can apply the conceptual framework for digital publishing production processes to adjust their production process to be clearer and more systematic. The quality of media will be increased and it can decrease the working time. This conceptual framework can be developed into an information system and applied to the system actually works. Moreover, producers should consider some details of this production process; for example, digital copyright management is something that can develop and complete the digital publishing production process.

\section{CONFLICT OF INTEREST}

The authors declare no conflict of interest.

\section{AUTHOR CONTRIBUTIONS}

Chaiwat Garnrunsri conducted the research and wrote the paper; Prachyanun Nilsook and Panita Wannapiroon reviewed and improved the paper; all authors had approved the final version.

\section{ACKNOWLEDGMENTS}

The researchers would like to thank MACeducation Co., Ltd. and King Mongkut's University of Technology North Bangkok, for their full support of this research.

\section{REFERENCES}

[1] M. Bunsiriphan, Print Media Situation, Nonthaburi: Sukhothai Thammathirat Open University Press, 2007.

[2] Y. Zhao and X. Huang, A Research on Development Mode Innovation of Digital Publishing Industry in the Age of Big Data, 2014.

[3] Y. Tian and J. Chen, "A research on architecture of digital publishing management system," Computer and Information Science, vol. 3, no. 3 , pp. 66-70, 2010.

[4] Y. Cao, "A perspective on digital publishing strategy in China: A case study on SPDG," presented at 2009 International Conference on Management and Service Science, Wuhan, China: IEEE, 2009.

[5] J. Khlaisang, "Digital publishing for net-generation learners," in Proc. 2012 National e-Learning Conference Integrating ASEAN Online Learning: Policy and Process, pp.53-62, Bangkok, Thailand, 2012.

[6] D. Babeanu, A. A. Gavrila, and V. Mares, Strategic Outlines: Between Value and Digital Assets Management, Annales Universitatis Apulensis Series Oeconomica, 2009.

[7] M. Bartoszewicki, Designing and Building an Interactive eBook, 2013.

[8] X. Chen, Analysis for Digital Content Industry Value Chain, 2009.
[9] H. Li and Y. Liu, "Workflow and its implementation of digital-publishing based on KaaS," in Proc. 2011 International Conference on Computer Science and Service System (CSSS), pp. 4141-4145, Nanjing, China: IEEE, 2011.

[10] M. Moon, "Cycle time: Activity lifecycle of digital assets," Journal of Digital Asset Management, vol. 3, no. 3, pp. 112-115, 2007.

[11] V. Padmanabhan and B. V. Sriharsha, Content Magnetisation Strategies for the Digital Publisher, Bangalore: Wipro Council for Industry Research, 2012.

[12] C. WichianPanya, "Digital asset management: Challenges of organizations in a knowledge-based social economy," Rangsitsarasonthet, vol. 20, no. 2, pp. 96-110, 2014.

[13] D. Zhonghua and C. Liguo, "The research of digital publishing resources management in China," 2008 IEEE International Symposium on IT in Medicine and Education, pp. 349-353, Xiamen, China : IEEE, 2008.

[14] J. W. Best and J. V. Kahn, Research in Education, America: A Viacom Company, 1998.

[15] K. Mingsirithum and S. Sudsawad, Development of Online Training Kits to Produce Electronic Books for Teachers in the Secondary Educational Service Area Office 3, Bangkok: Sukhothai Thammathirat Open University, 2012.

Copyright (C) 2020 by the authors. This is an open access article distributed under the Creative Commons Attribution License which permits unrestricted use, distribution, and reproduction in any medium, provided the original work is properly cited (CC BY 4.0).

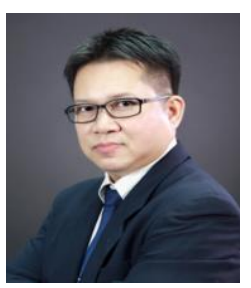

Chaiwat Garnrunsri is a Ph.D. candidate, the Department of Technical Education Technology, Faculty of Technical Education, King Mongkut's University of Technology North Bangkok (KMUTNB) and he is assistant managing director at MACeducation Co., Ltd., Bangkok, Thailand.

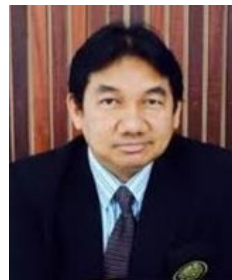

Prachyanun Nilsook is an associate professor at the Division of Information and Communication Technology for Education, Faculty of Technical Education, and Director of Technical Vocational Education Research Center, and Science and Technology Research Institute (STRI), King Mongkut's University of Technology North Bangkok (KMUTNB), Bangkok, Thailand.

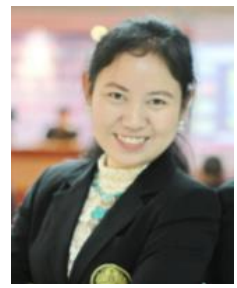

Panita Wannapiroon is an associate professor at the Division of Information and Communication Technology for Education, Faculty of Technical Education, Director of Innovation and Technology Management Research Center (ITMRC), and Science and Technology Research Institute (STRI), King Mongkut's University of Technology North Bangkok (KMUTNB), Bangkok, Thailand. 